\title{
COMUNICAÇÃO ALTERNATIVA COMO INSTRUMENTO EXTERNO DE COMPENSAÇÃO: POSSIBILIDADES PARA A APRENDIZAGEM DE ALUNOS COM MÚLTIPLAS DEFICIÊNCIA ${ }^{i}$
}

\author{
Maíra Gomes de Souza da Rocha ${ }^{\text {ii }}$ \\ Márcia Denise Pletsch ${ }^{\text {iii }}$
}

\begin{abstract}
Resumo: O texto reflete sobre o uso da comunicação alternativa (CA) como ferramenta para possibilitar os processos de aprendizagem e desenvolvimento de alunos com múltiplas deficiências não usuários da linguagem oral. Empregamos os referenciais da pesquisa qualitativa utilizando como procedimentos de coleta de dados observações com registro em diário de campo, entrevistas semiestruturadas e abertas, assim como filmagens das práticas docentes. A pesquisa foi realizada com duas professoras do Atendimento Educacional Especializado (AEE) de uma escola pública da Baixada Fluminense e quatro alunos com múltiplas deficiências por elas atendidos. Com base na perspectiva histórico-cultural nossos resultados, entre outras questões, evidenciaram possibilidades de aprendizagem desses sujeitos; a importância da utilização de recursos de CA, os quais em função das especificidades dos sujeitos com múltiplas deficiências acabavam funcionando como instrumentos de compensação em benefício do processo de ensino e aprendizagem destes alunos.
\end{abstract}

Palavras-chave: Deficiência múltipla. Comunicação alternativa. Processos de ensino e aprendizagem.

\section{ALTERNATIVE COMMUNICATION AS AN EXTERNAL COMPENSATION INSTRUMENT: POSSIBILITIES FOR THE LEARNING OF STUDENTS WITH MULTIPLE DEFICIENCIES}

\begin{abstract}
The text reflects on the use of alternative communication as a tool to enable the processes of learning and students development with multiple disabilities non-users of oral language. We use the qualitative research references using as data collection procedures with record in field journal, semi structured and open interviews, as well as filming of teaching practices. The research was carried out with two Specialized Educational Service (SES) teachers of a public school in the Baixada Fluminense Region and four students with multiple disabilities attended by them. Based on historical-cultural perspective our results, among other issues, highlighted learning possibilities of these subjects; the importance of use of AC resources, which according to the subjects with multiple disabilities specificities ended up functioning as clearing instruments that benefits teaching and learning process of the students.
\end{abstract}

Keywords: Multiple disabilities. Alternative communication. Teaching and learning processes. 


\section{Introdução}

Entendemos que a deficiência múltipla é constituída pela associação entre duas ou mais deficiências primárias (intelectual/física/sensorial), com impactos muito variáveis na vida de uma pessoa. Podendo ocorrer em várias combinações de deficiências, variando conforme o número, a natureza, o grau e a abrangência das deficiências em questão; consequentemente, variam os efeitos dos comprometimentos na vida e prática das pessoas que a apresentam. É pertinente mencionar que após análise da literatura nacional e internacional disponível nas principais bases de dados científicos como Scielo, Lilacs, Index Psi, PePSIC e no Google Acadêmico, verificamos que existem contradições e falta de consenso na definição do que seria a deficiência múltipla (ROCHA; PLETSCH, 2015; ROCHA, 2017).

A deficiência múltipla pode ter impactos enormes na vida da pessoa e para realizarmos intervenções educacionais adequadas é importante analisar seus efeitos na funcionalidade do sujeito frente ao seu ambiente e à realidade em que vive. Nessa direção, temos percebido avanços interessantes a partir da ampliação das diretrizes políticas sobre inclusão educacionais. No entanto, o processo de escolarização de alunos com múltiplas deficiências ainda se configura como um desafio para as escolas. Além disso, são poucas as pesquisas sobre essa deficiência no contexto educacional (SILVEIRA; NEVES, 2006; ROCHA, 2014; PLETSCH, 2018).

Para garantir o processo de aprendizagem e desenvolvimento destes alunos é importante refletir sobre as necessidades educacionais especiais apresentadas por cada indivíduo a fim de buscar adequações de infraestrutura, de materiais, do currículo escolar, das práticas que lhe são direcionadas e em tantos outros aspectos necessários para que o desenvolvimento destes alunos seja beneficiado.

Tomando essa realidade como pano de fundo, desde 2012 temos realizado um conjunto de pesquisas sobre a escolarização de alunos com múltiplas deficiências, assim como os programas educacionais e a estrutura e o funcionamento de suporte pedagógico oferecido para estes sujeitos no contexto escolar. Aqui apresentaremos parte dos resultados da primeira pesquisa realizada entre 2012 e 2014 que culminou a defesa da dissertação "Processos de ensino e aprendizagem de alunos com múltiplas deficiências no AEE à luz da teoria histórico-cultural" (ROCHA, 2014) realizada no âmbito dos projetos desenvolvidos no Observatório de Educação Especial e Inclusão Educacional (ObEE) $)^{\mathrm{iv}}$.

Aqui, neste artigo, apresentamos uma reflexão sobre o uso da comunicação alternativa (CA) - área pertencente à tecnologia assistiva (TA) - como ferramenta para possibilitar os processos de aprendizagem e desenvolvimento de alunos com múltiplas deficiências não 
usuários da linguagem oral. Para atingir nosso objetivo, realizamos uma pesquisa qualitativa em que acompanhamos práticas de duas professoras do Atendimento Educacional Especializado (AEE) para quatro alunos com múltiplas deficiências, em uma escola pública da Baixada Fluminense. Os quadros a seguir sintetizam informações sobre os participantes.

Quadro 1. Caracterização dos alunos participantes

\begin{tabular}{|c|c|c|}
\hline Nomes $^{v}$ & Idade & Descrição dos alunos \\
\hline Igor & $\begin{array}{c}9 \\
\text { anos }\end{array}$ & $\begin{array}{l}\text { Tendo Síndrome de Down e surdez, o aluno apresenta grande dificuldade em se } \\
\text { controlar, principalmente quando se sente contrariado. Nestes momentos, costuma } \\
\text { reagir através de agressões físicas ou com o arremesso de objetos. A manifestação de } \\
\text { sua linguagem se dá através de gritos e outras emissões de sons. }\end{array}$ \\
\hline Fernando & $\begin{array}{c}12 \\
\text { anos }\end{array}$ & $\begin{array}{l}\text { Com o diagnóstico de paralisia cerebral, apresenta significativas dificuldades } \\
\text { motoras e deficiência intelectual - além de não andar não tem controle de tronco e } \\
\text { dos membros superiores. Sua oralidade é consideravelmente comprometida. }\end{array}$ \\
\hline Marc & $\begin{array}{c}10 \\
\text { anos }\end{array}$ & $\begin{array}{l}\text { Com encefalopatia crônica da infância, é cadeirante e tem necessidades de } \\
\text { adequação postural. Apresenta severos comprometimentos motores e cognitivos. } \\
\text { Com ausência da fala, se manifesta através de expressões faciais e sutis emissões de } \\
\text { sons. }\end{array}$ \\
\hline Eliza & $\begin{array}{c}18 \\
\text { anos }\end{array}$ & $\begin{array}{l}\text { O laudo aponta paraplegia sensório-motora/ mielomeningocele lombar operado/ } \\
\text { hidrocefalia/ problemas de percepção viso-motora. Tem grande sensibilidade } \\
\text { auditiva, ficando muito agitada quando há barulho ou sons estridentes. Além das } \\
\text { dificuldades motoras, também apresenta deficiência intelectual. Não apresenta } \\
\text { oralidade, emitindo ruídos quando está incomodada com algo. }\end{array}$ \\
\hline
\end{tabular}

Fonte: Banco de dados ObEE (2014).

Quadro 2. Caracterização das docentes participantes

\begin{tabular}{|c|c|c|c|c|}
\hline Docentes & $\begin{array}{c}\text { Sala de Recursos } \\
\text { Multifuncionais }\end{array}$ & \multicolumn{1}{|c|}{ Formação Inicial } & $\begin{array}{c}\text { Tempo no } \\
\text { Magistério }\end{array}$ & $\begin{array}{c}\text { Tempo de } \\
\text { atuação na } \\
\text { sala }\end{array}$ \\
\hline Ruth & SR A & $\begin{array}{l}\text { Graduada em Pedagogia com } \\
\text { habilitação em Magistério e } \\
\text { Educação } \\
\text { Especialização para o AEE e } \\
\text { transtornos globais do } \\
\text { desenvolvimento. }\end{array}$ & 7 anos \\
\hline Claudia & SR B & $\begin{array}{l}\text { Graduada em Pedagogia e } \\
\text { Especialização em Educação } \\
\text { Especial. }\end{array}$ & 9 anos & 1 ano \\
\hline
\end{tabular}

Fonte: Banco de dados ObEE (2014).

Em termos metodológicos usamos os referenciais da pesquisa qualitativa e como procedimento de coleta de dados realizamos observação participante (com registro em diário de campo) no acompanhamento das atividades na sala de AEE; análise de imagens de vídeo pautada na abordagem microgenética (GÓES, 2000); entrevistas abertas e semiestruturadas (com gravação em áudio) com as professoras participantes. Para a análise dos dados, optamos por utilizar a técnica conhecida como "análise de conteúdo", conforme disposto em Minayo (1994). 
Após o cumprimento das etapas que esta técnica propõe, realizamos a "triangulação dos dados" coletados para a validação dos mesmos (GLAT; PLETSCH, 2012).

Como referencial teórico, a perspectiva histórico-cultural de Vigotski foi usada pelas inovações que apresenta a respeito do desenvolvimento humano; inclusive quando este ocorre de modo peculiar como no caso das pessoas que apresentem algum tipo de deficiência. Especificamente, nos reportamos à ideia de compensação ${ }^{\text {vi }}$ trabalhada por Vigotski no estudo do campo da defectologia (VIGOTSKI, 1997). Na defectologia, o teórico buscou o aprofundamento de formas alternativas, bem como recursos especiais para a aprendizagem e desenvolvimento de crianças com deficiência.

Segundo Vigotski, o processo de compensação não é a cura da deficiência, mas propicia o desenvolvimento de áreas potenciais. Vigotski compreende a compensação como uma reação da personalidade ante a deficiência no processo de desenvolvimento da criança com defeito. $\mathrm{O}$ conflito que geralmente acontece por causa da deficiência, trazendo dificuldades para a vida do sujeito também pode criar possibilidades e estímulos de compensação. O defeito torna-se, portanto, o ponto de partida e principal força motriz por trás do desenvolvimento psíquico da personalidade (VIGOTSKI, 1997). Assim, por meio do desenvolvimento cultural que o sujeito pode ter, caminhos alternativos à deficiência podem ser trilhados para melhorar não somente a qualidade de vida, mas beneficiar processos de aprendizagem.

Em outros termos, como já discutido por Pletsch (2015) a partir das colocações de Vigotski (1997), como exemplos de compensação, podemos dizer que para o cego o mecanismo acionado é o aprendizado do Braille, ao passo que para o surdo é o aprendizado de Libras. Ambos são recursos aprendidos que atuam na organização do pensamento e da linguagem. Segunda a mesma autora, no caso dos alunos com deficiência múltipla, a principal ferramenta de compensação pode ser considerada a linguagem (falada ou com uso de símbolos alternativos), mediante a interação e os enunciados e desafios propostos aos sujeitos. Como os sujeitos de nossa pesquisa não eram usuários da linguagem oral, a comunicação alternativa foi usada como recurso externo para compensar a não fala e dessa forma propiciar a interação e a comunicação dos sujeitos.

A comunicação alternativa envolve desde gestos e expressões faciais, a diversas formas gráficas, como modo de efetuar a comunicação de pessoas que não conseguem utilizar a linguagem verbal. Ainda, considera os propósitos de promover e suplementar a fala e o de garantir uma nova alternativa, caso não haja a possibilidade de desenvolvê-la "A comunicação é considerada alternativa quando o indivíduo não apresenta outra forma de comunicação e, considerada ampliada quando o indivíduo possui alguma comunicação, ou essa não é suficiente Revista Interinstitucional Artes de Educar. Rio de Janeiro, V. 4, N.1- pág. 174 - 185 - (jan. - abr. de 2018): "Questões contemporâneas sobre a Educação Especial na Perspectiva da Educação Inclusiva" - 
para suas trocas sociais" (PELOSI, 2000, p.35). A escolha da CA também foi importante pelo fato de nos possibilitar a construção de recursos de baixo custo e assim efetivamente poder fazer parte da prática pedagógica independentemente da presença de recursos de média ou alta tecnologia (ROCHA; PLETSCH, 2013). Essas premissas teóricas fundamentam nossa análise que será apresentada a seguir.

\section{Considerações sobre a CA como ferramenta para a compensação}

A discussão sobre o conceito de compensação com as professoras nos levou a reflexões diversas que foram se concretizando por meio de mudanças em suas práticas pedagógicas. $\mathrm{O}$ entendimento de que o processo de compensação pode colaborar diretamente para os processos de aprendizagem dos alunos com deficiência múltipla estimulou a identificação de potencialidades que poderiam ser desenvolvidas por meio de uma mediação pedagógica diferenciada. O relato de uma das docentes exprime a questão, bem como a consciência de que a compensação não garante sempre o sucesso na aprendizagem:

\footnotetext{
Estou gostando de estudar sobre a compensação porque me estimula a buscar meios e alternativas que venham a contribuir para a aprendizagem dos meus alunos. Sendo diferente o funcionamento do seu desenvolvimento, entendo que tenho que atender as suas particularidades para que ele aconteça. Isso é compensar! Ainda assim, também entendi que não podemos achar que a compensação vai garantir que ele venha a aprender tudo o que eu espero (Gravação em áudio, 13/11/13).
}

Como já sinalizamos a deficiência existente numa criança leva a mesma a querer compensá-la, trilhar outros caminhos de desenvolvimento. Um indivíduo cego reage contra a sua cegueira; bem como o outro com uma deficiência psíquica tenta compensá-la através da interação com o meio. A compensação pode ter diferentes desfechos, contudo, qualquer que seja o seu resultado, o desenvolvimento complicado pela deficiência constitui sempre um processo criador e de construção (VIGOTSKI, 1997).

Estas proposições de Vigotski foram importantes nas reflexões com as professoras. No início da pesquisa, ao abordar sobre os processos de ensino e aprendizagem, víamos que mediante as peculiaridades dos alunos e seus comprometimentos, as professoras pareciam não acreditar haver caminhos para a aprendizagem. Vejamos outra colocação realizada por uma delas já ao longo do estudo:

Vendo todas estas limitações do nosso aluno, a gente tenta fazer o estímulo onde se percebe que tem uma entrada maior. Porque se tem uma deficiência auditiva, Vigotski fala da compensação dessa deficiência, então, se a gente estimular a outra parte, de 
repente se consegue atingir aquele aluno. A gente precisa encontrar esse canal onde o aluno tem maior receptividade, onde ele consegue. É questão de trilhar um outro caminho, aquele caminho que o biológico não permite, mas que pela cultura a gente consegue trilhar um diferente para alcançar aquele objetivo. Não é que o aluno vai deixar de ter deficiência. Acho que essa é a essência também da compensação (Gravação em áudio, 13/11/13).

Notou-se, portanto, a necessidade de se impetrar esforços para que a mediação pedagógica propiciasse aos educandos o desenvolvimento de mecanismos de compensação. No acompanhamento dos educandos com deficiência múltipla, percebeu-se a complexidade deste trabalho, exigindo que as professoras tivessem um olhar atento aos mínimos detalhes que pudessem evidenciar esta questão, ainda mais porque estes educandos apresentam associadas diferentes modalidades de deficiências.

Neste ponto, levando-se em consideração as limitações motoras e de comunicação apresentadas pelos alunos alvo da pesquisa, pontuamos as possibilidades que observamos através do uso de tecnologias assistivas - área a qual pertence a comunicação alternativa - funcionando como instrumentos externos para viabilizar processos de compensação. Para ilustrar este aspecto, destacamos a fala de uma das professoras durante entrevista realizada:

Pesquisadora: Como o acesso ao conhecimento das áreas de tecnologias assistivas e da comunicação alternativa pode colaborar para os processos de ensino e aprendizagem com alunos deficientes múltiplos?

Professora: Já começa aí na questão da compensação... a tecnologia assistiva já ajuda nisso. A gente tem um aluno que tem uma dificuldade, e aí a gente quer usar um outro canal um pouco mais aberto; essa tecnologia vai ajudar justamente nesse canal (Gravação em áudio, 13/11/13).

Também identificamos que o uso dos conhecimentos obtidos na área da comunicação alternativa poderia viabilizar o processo de compensação em relação às limitações na oralização dos alunos. O episódio a seguir exemplifica esta constatação:

\begin{tabular}{|c|c|c|c|l|}
\hline Data & Local & Horário & $\begin{array}{l}\text { Duração do } \\
\text { episódio }\end{array}$ & \multicolumn{1}{|c|}{ Descrição } \\
\hline $21 / 08$ & $\begin{array}{c}\text { Sala de } \\
\text { recursos } \\
\text { multifuncionais }\end{array}$ & $10: 17 \mathrm{~h}$ & $00: 02: 20$ & $\begin{array}{l}\text { Fernando pergunta algo para a } \\
\text { pesquisadora. Tentamos entender: primeiro } \\
\text { achamos que ele está perguntando onde } \\
\text { mora, depois perguntamos se ele está se } \\
\text { referindo a jogar bola (...) O aluno tenta } \\
\text { fazer-se entender mas, não conseguimos - } \\
\text { comentamos sobre a importância dele ter } \\
\text { acesso a um trabalho específico de } \\
\text { comunicação alternativa uma vez que o que } \\
\text { o prejudica mais, muitas das vezes é a } \\
\text { dificuldade em se comunicar. }\end{array}$ \\
\hline
\end{tabular}

Fonte: Vinheta confeccionada a partir das transcrições de vídeo sistematizadas por Rocha (2014). 
A partir dessas considerações, começamos a discutir com as professoras como a comunicação alternativa poderia ser utilizada como instrumento para a compensação desta dificuldade na oralização dos sujeitos. Além de considerar que ela colaboraria a longo prazo na comunicação, também tínhamos em mente toda a discussão sobre a importância da linguagem para a aprendizagem realizada em encontros anteriores. A fala de uma das professoras ilustra o seu entendimento da utilização da CA para o desenvolvimento da linguagem, trazendo benefícios para o processo de aprendizagem:

Temos aprendido o quanto a linguagem é fundamental para a aprendizagem. Assim, se o meu aluno não pode falar e eu sei que a linguagem é muito mais que isso, preciso encontrar formas dele desenvolvê-la ainda que não seja do jeito tradicional. Neste ponto, vejo que a comunicação alternativa ajuda muito, não só para os sujeitos poderem “falar”, mas também raciocinar (Gravação em áudio, 13/11/13).

Neste sentido já havia o consenso na equipe envolvida na pesquisa de que a comunicação alternativa poderia colaborar para o desenvolvimento da aprendizagem não se constituindo apenas como elemento compensatório para a comunicação, mas para a construção de esquemas mais abstratos como os que envolvem o próprio pensamento, beneficiando assim, a aprendizagem. Vejamos episódio que ilustra esta questão:

\begin{tabular}{|c|c|c|c|l|}
\hline Data & Local & Horário & $\begin{array}{c}\text { Duração } \\
\text { do } \\
\text { episódio }\end{array}$ & \multicolumn{1}{c|}{ Descrição } \\
\hline $21 / 08$ & $\begin{array}{c}\text { Sala de } \\
\text { recursos } \\
\text { multifuncion } \\
\text { ais }\end{array}$ & $09: 23 \mathrm{~h}$ & $00: 02: 24$ & $\begin{array}{l}\text { Ruth mostra para o aluno a miniatura de } \\
\text { um leão. Imita novamente o leão e o } \\
\text { associa à imagem do animal nos slides. A } \\
\text { professora fala do seu pelo, destacando } \\
\text { que é macio. Para tanto, ela pega um } \\
\text { bichinho de pelúcia para o aluno sentir } \\
\text { esta maciez. Marcelo observa quietinho } \\
\text { [..]. A professora aponta que o pelo das } \\
\text { vacas também é macio e novamente passa } \\
\text { a pelúcia no aluno. }\end{array}$ \\
\hline
\end{tabular}

Fonte: Vinheta confeccionada a partir das transcrições de vídeo sistematizadas por Rocha (2014).

Esta vinheta com o aluno Marcelo ilustra a utilização de ideias e recursos de comunicação alternativa de baixa tecnologia que se tornaram recorrentes na prática pedagógica das professoras ao longo da pesquisa (neste caso, miniaturas dos animais e as imagens nos slides). A utilização de materiais e estratégias provenientes dessa área para que se constituíssem como instrumentos de compensação era avaliada de acordo com as peculiaridades de desenvolvimento apresentadas pelos alunos. Deste modo, assim como a utilização de miniaturas era adequada para Marcelo, que tinha muita dificuldade de abstração, para outros alunos como 
Fernando já se via a possibilidade de iniciar o trabalho com sistemas gráficos de comunicação. Vejamos a seguir um exemplo:

\begin{tabular}{|c|c|c|c|l|}
\hline Data & Local & Horário & $\begin{array}{c}\text { Duração } \\
\text { do episódio }\end{array}$ & \multicolumn{1}{|c|}{ Descrição } \\
\hline $19 / 06$ & $\begin{array}{c}\text { Sala de } \\
\text { recursos } \\
\text { multifuncionais }\end{array}$ & $10: 21 \mathrm{~h}$ & $00: 01: 03$ & $\begin{array}{l}\text { A professora está mostrando slides com } \\
\text { símbolos do sistema PCS. Mostra um } \\
\text { respectivo a estar zangado pergunta se } \\
\text { Fernando está assim, ele responde que } \\
\text { sim balançando a cabeça e sorrindo. A } \\
\text { professora pergunta o que aconteceu } \\
\text { para ele ficar zangado, lembrando-o de } \\
\text { que ele tinha dito que estava feliz. }\end{array}$ \\
\hline
\end{tabular}

Fonte: Vinheta confeccionada a partir das transcrições de vídeo sistematizadas por Rocha (2014).

A identificação das possibilidades provenientes das tecnologias assistivas, bem como da comunicação alternativa como instrumentos de compensação foi sendo explorada ao longo da pesquisa. Além da percepção de como poderiam ser utilizados pela prática pedagógica, era necessário adquirir materiais ou construir quando isso era possível.

A este respeito, vale registar que por meio do financiamento que a pesquisa recebeu foi possível adquirir para o trabalho pedagógico com os alunos, equipamentos que oportunizassem a utilização de recursos da área das tecnologias assistivas e, a partir da comunicação alternativa. Além da utilização desses equipamentos, as professoras passaram a construir materiais de baixa tecnologia pertinentes à comunicação.

Para a confecção dos referidos materiais, mediante ao curto espaço de tempo que uma pesquisa de mestrado costuma ter, bem como a necessidade que há de maior sistematização educacional destes alunos, optamos, em pleno acordo com as professoras, focalizar materiais que não fossem muito complexos.

Neste sentido, cartões e pranchas passaram a ser construídos utilizando fotos ou gravuras que já fossem familiares aos alunos. Aspecto importante para não cairmos no equívoco de exigir um grau de abstração que fosse além das atuais possibilidades dos educandos.

Ainda sobre tal aspecto, até mesmo a gradativa inserção de símbolos mais sistematizados com os alunos Fernando e Eliza foi realizada, utilizando pranchas com poucas imagens. A escolha do sistema simbólico PCS (Sistema Pictográfico de Comunicação) em meio a tantos outros, foi devido à simplicidade de seus contornos e objetividade das informações. Para a utilização destes símbolos, primeiramente era realizada a associação de suas imagens com gravuras reais para facilitar a sua significação. A partir do que foi realizado, evidenciamos que o 
trabalho com esses recursos entendidos como ferramentas para propiciar a compensação foi bem sucedido.

Sabemos que falta muito para que esses progressos venham a se consolidar de fato, mas que podem fazer a diferença não somente nos processos de ensino e aprendizagem, mas na vida desses sujeitos. O episódio a seguir ajuda a exprimir esta nossa constatação:

\begin{tabular}{|l|l|l|l|l|}
\hline Data & Local & Horário & $\begin{array}{l}\text { Duração do } \\
\text { episódio }\end{array}$ & \multicolumn{1}{|c|}{ Descrição } \\
\hline $21 / 08$ & $\begin{array}{l}\text { Sala de recursos } \\
\text { multifuncionais }\end{array}$ & $10: 26 \mathrm{~h}$ & $00: 05: 40$ & $\begin{array}{l}\text { Em meio à atividade, Fernando fala algo } \\
\text { que ninguém consegue compreender } \\
\text { (..). Sobre este impasse na na } \\
\text { comunicação, Ruth diz para Fernando } \\
\text { que quando a mãe dele chegar vai } \\
\text { perguntar a ela o que ele está querendo } \\
\text { falar. A pesquisadora fala para Fernando } \\
\text { que ele aprender a escrever no } \\
\text { computador, ele vai ter mais facilidade } \\
\text { de se comunicar (ele ouve e concorda } \\
\text { balançando a cabeça). Ele tenta } \\
\text { perguntar alguma coisa (perguntamos se } \\
\text { é sobre bola, se é sobre namorado...). Ele } \\
\text { exclama: "Ah Jesus!" (comentamos que } \\
\text { ele é bem humorado, se não já estaria } \\
\text { "batendo" na gente). Damos a ideia dele } \\
\text { continuar a atividade enquanto tentamos } \\
\text { entender o que ele disse. Ele insiste (...). } \\
\text { Percebe-se o esforço do aluno tentando } \\
\text { falar mais alto ou pausadamente para ser } \\
\text { compreendido. }\end{array}$ \\
\hline
\end{tabular}

Fonte: Vinheta confeccionada a partir das transcrições de vídeo sistematizadas por Rocha (2014).

Situações como estas nos mostram o quanto alternativas diferenciadas para a comunicação podem fazer a diferença na vida de uma pessoa. A insistência do aluno para se fazer compreender e em não aceitar que fizéssemos interpretações erradas da sua intenção comunicativa, nos levou a pensar nas novas conquistas que ele alcançará se tiver a oportunidade de compensar a sua limitação na fala.

A partir das análises realizadas é possível reforçar que a relação entre linguagem e compensação foi sendo constituída a partir do uso de recursos da comunicação alternativa nas práticas pedagógicas. De fato, mais pesquisas precisam ser realizadas para aprofundar tal relação, inclusive com sujeitos que não apresentam dificuldades tão acentuadas na linguagem. Todavia, nossas análises indicam pistas para novas investigações a partir das considerações que destacamos. 


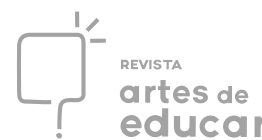

Vale ressaltar que além dessas possibilidades dos recursos de tecnologias assistivas e comunicação alternativa como instrumentos externos de compensação, a pesquisa verificou que estudantes com múltiplas deficiências tem potencialidades de aprendizagem que precisam ser exploradas. Para tanto, recursos e estratégias adequadas precisam ser disponibilizados na prática pedagógica e no processo de escolarização.

A este respeito, também cabe destacar, que o estudo demonstrou a necessidade e urgência das políticas públicas de inclusão estarem efetivamente próximas da realidade de indivíduos com deficiências como a múltipla. Diferentes formas de prestação de serviços (de saúde, de transporte, articulação entre diferentes setores...), bem como o próprio atendimento educacional precisam ser pertinentes à condição destas pessoas a fim de que venham a colaborar para maior qualidade de vida e possibilidades de integração social e desenvolvimento. $\mathrm{O}$ acesso a recursos de TA e CA por exemplo, devem ser garantidos.

\section{Considerações finais}

Este artigo objetivou apresentar reflexões sobre o uso da comunicação alternativa como ferramenta para possibilitar os processos de aprendizagem e desenvolvimento de alunos com múltiplas deficiências não usuários da linguagem oral. Certamente não esgotamos o tema e novos estudos deverão ser realizados. Contudo, alguns resultados da investigação podem ser sistematizados.

Os dados mostraram que apesar dos comprometimentos apresentados por alunos com deficiência múltipla, estes apresentam potenciais de aprendizagem que não podem ser subestimados. A importância de um ensino formal e sistematizado evidenciou-se a cada acompanhamento realizado no AEE, demonstrando que é fundamental garantir a escolaridade a partir de práticas que contribuam para progressos na aprendizagem e não apenas avanços na socialização. Neste sentido, as políticas de inclusão também devem contribuir para que haja melhores condições para a realização deste trabalho. Certamente sistemas de suporte especializado para além do AEE precisam ser propostos, pois muitos dos sujeitos demandam também suporte especializado em sala de aula e não apenas durante o atendimento no contra turno.

A relevância de um trabalho contínuo e bem direcionado às necessidades educacionais também se mostrou fundamental. O trabalho pedagógico não pode ignorar os impactos relacionados às especificidades apresentadas por conta das múltiplas deficiências. A este respeito, os recursos de TA, em especial os de comunicação alternativa, associados a mediação 
pedagógica pelas professoras, contribuem para ampliar as possibilidades de compensação e aprendizagem dos alunos com múltipla deficiência.

Por último, os dados revelaram que garantir acesso ao ambiente escolar não basta, são necessários investimentos financeiros para melhorar a estrutura física, o acesso a recursos de comunicação alternativa. Mas, sobretudo, garantir aos docentes condições de trabalho e formação continuada. Igualmente, são necessários investimentos em pesquisas sobre as inúmeras dimensões que envolvem o debate sobre a escolarização de sujeitos com deficiências múltiplas, em especial, nos casos mais graves.

\section{Referências bibliográficas}

BRASIL, Programa de Capacitação de Recursos Humanos do Ensino Fundamental: Deficiência Múltipla. Brasília, DF: Ministério da Educação, Secretaria de Educação Especial. (Série Atualidades Pedagógicas). Brasília, 2000.

DAINEZ, D. Constituição Humana, Deficiência e Educação: Problematizando o Conceito de Compensação na Perspectiva Histórico-Cultural. Tese de Doutorado. Programa de PósGraduação em Educação. Universidade Estadual de Campinas. Campinas/SP, 2014.

GLAT, R.; PLETSCH, M. D. Inclusão escolar de alunos com necessidades educacionais especiais. Série Pesquisa em Educação. Editora EduERJ, RJ, 2012.

GÓES, M. C. R. de. A abordagem microgenética na matriz histórico-cultural: uma perspectiva para o estudo da constituição da subjetividade. In: Cadernos Cedes, ano XX, n 50, Abril, 2000.

MINAYO, M. C. Pesquisa social - teoria, método e criatividade. Petrópolis: Vozes, 1994.

PELOSI, M. B. A comunicação alternativa e ampliada nas escolas do Rio de Janeiro: formação de professores e caracterização dos alunos com necessidades educacionais especiais.

Dissertação (Mestrado em Educação) UERJ, 2000.

PLETSCH, M. D. Deficiência múltipla: formação de professores e processos de ensinoaprendizagem. Cadernos de Pesquisa, v. 45, p. 12-29, 2015.

PLETSCH, M. D. Escolarização e desenvolvimento de alunos com deficiência intelectual e múltipla. Relatório de Pesquisa. Nova Iguaçu, 2018.

ROCHA, M. G. de S. da.; PLETSCH, M. D. O Atendimento Educacional Especializado (AEE) para alunos com múltiplas deficiências frente às políticas de inclusão escolar: um estudo sobre as práticas pedagógicas. In: Revista Aleph (UFF. Online), v. VIII, p. 229-243, 2013. 
ROCHA, M. G. de S. da. Processos de ensino e aprendizagem de alunos com múltiplas deficiências no AEE à luz da teoria histórico-cultural. 2014. 233 p. Dissertação (Mestrado em Educação) Instituto de Educação / Instituto Multidisciplinar / PPGEduc / Universidade Federal Rural do Rio de Janeiro, Nova Iguaçu, RJ. 2014.

ROCHA, M. G. de S. da.; PLETSCH, M. D. Deficiência múltipla: disputas conceituais e políticas educacionais no Brasil. In: Revista Cadernos de Pesquisa. v. 22, n. 1, São Luís, MA, jan./abr. 2015.

ROCHA, M. G. de S. da. A escolarização como princípio para o desenvolvimento humano de alunos com múltiplas deficiências. Texto de Qualificação de Tese. Doutorado em Educação. Programa de Pós-Graduação Em Educação, Contextos Contemporâneos e Demandas Populares (PPGEduc). Universidade Federal Rural do Rio de Janeiro. Nova Iguaçu, 2017.

SILVEIRA, F. F.; NEVES, M. M. B. J. Inclusão Escolar de Crianças com Deficiência Múltipla: Concepções de Pais e Professores. In: Psicologia: Teoria e Pesquisa Vol. 22 n. 1, pp. 079-088, Jan-Abr 2006.

VIGOTSKI, L. S. Fundamentos da defectologia (Obras escogidas) volume V. Visor. Madrid, 1997.

\section{${ }^{\text {i }}$ Financiamento: OBEDUC/CAPES; FAPERJ e CNPq.}

ii Mestre e doutoranda pelo Programa de Pós-Graduação em Educação, Contextos Contemporâneos e Demandas Populares (PPGEduc/UFRRJ). Rio de Janeiro. Professora e Orientadora Pedagógica da Rede Municipal de Ensino de Duque de Caxias/RJ.

iii Professora Associada do Departamento Educação e Sociedade e do Programa de PósGraduação em Educação, Contextos Contemporâneos e Demandas Populares (PPGEduc) da Universidade Federal Rural do Rio de Janeiro (UFRRJ). Jovem Cientista da Faperj e Pesquisadora do CNPq.

${ }^{\text {iv }}$ Disponível em: http://r1.ufrrj.br/im/oeeies/

${ }^{v}$ Os nomes utilizados, tanto dos alunos quanto das professoras, são fictícios para a preservação da identidade dos mesmos. O projeto foi aprovado no comitê de ética da UFRRJ com número de Protocolo 272/2012.

${ }^{\text {vi }}$ Para um aprofundamento sobre a gênese desse conceito sugerimos a leitura da Tese de Dainez (2014). 